\title{
AKT FUNDACYJNY PREPOZYTURY W BENEDYKTYŃSKICH KSIĄŻNICACH WIELKICH Z R. 1508
}

Celem niniejszej publikacji jest wydanie drukiem pochodzącego z r. 1508 dokumentu erekcyjnego prepozytury i mansjonarii w Książnicach Wielkich', wsi koło Koszyc, w dawnym powiecie proszowskim. Przez swoja niezwykłą drobiazgowość, wprost detaliczność, wnosi on wiele szczegółów do organizacji tych instytucji kościelnych.

Oryginalny dyplom pergaminowy, zaopatrzony pieczęcia, który widział M. Sokołowski, opracowujący w r. 1906 zabytkowy poliptyk książnicki, uchodzi obecnie za zaginiony ${ }^{2}$. Odpis tego dokumentu zachował się w kopiarzu mansjonarzy książnickich, skopiowanym ok. r. 1510. Kodeks ten, bardzo zniszczony, został zabezpieczony przez Mieczysława Kupiszewskiego, pochodzącego z Książnic Wielkich. W r. 1999 został wyrestaurowany na koszt parafii książnickiej przez konserwatora Annę Michaś i jest tam obecnie przechowywany. W Oddziale Rękopisów Biblioteki Jagiellońskiej znajduje się jego odbitka kserograficzna (sygn Fot. 435). Opis kodeksu zamieściłam $w$ artykule poświęconym tamtejszej bibliotece parafialnej ${ }^{3}$. Dodatkowo

${ }^{1}$ Do historii Książnic Wielkich zob. M. Sokołowski, Studia do historii rzeźby w Polsce w XV i XVI w. W: Sprawozdania Komisji do Badania Historii Sztuki w Polsce, 7, 1906, szp. 178-194, 227-240; J. W i śn i ew sk i, Historyczny opis kościołów, miast, zabytków i pamiątek $w$ pinczowskiem, skalbmierskiem $i$ wiślickiem, Marjówka 1927, s. 174-185; Katalog zabytków sztuki w Polsce, t. 3, z. 9, Powiat pińczowski, Warszawa 1961, s. 43; J. G u rd a, Parafia Ksiqżnice Wielkie, Zarys dziejów, Kielce 1992; a zwłaszcza bardzo dobrze źródłowo opracowane przez Z. Leszczyńską-Skrętową haslo Książnice Wielkie W: Stownik Historyczno-geograficzny województwa krakowskiego w Średniowieczu, cz. III z. 2, Kraków 1992 s. 327-332. Zob. też Corpus inscriptionum Poloniae, t. 1, pod red. J. S z ymań s ki e g o, z. 4, Kielce 1983, s. 110-114, nry 117-122.

${ }^{2}$ Zachowany w Archiwum Diecezjalnym w Kielcach „Privilegium seu erectio prepositurae cum mansionariis" (sygn. II PK XVII 1) jest kopią z XVIII w.

${ }^{3}$ M. K owalczyk, Biblioteka $w$ kościele parafialnym $w$ Ksiażnicach Wielkich, „Studia Mediewistyczne”, 33:1998, s. 187-197. 
trzeba może wyszczególnić, pominięte w opisie, kopie dokumentów, pozostających $\mathrm{w}$ związku $\mathrm{z}$ uposażeniem prepozytury książnickiej: $\mathrm{z}$ r. 1508 w sprawie zamiany dziesięcin we wsiach Modrzany i Dolany (k. 1r-2v), z r. 1478 dotyczący dziesięciny we wsi Majkowice (k. 4r-9v), oraz z r. 1492 zawierający przywilej dla chłopów z Książnic Wielkich na wypas bydła (k. $9 v-12 v)$.

Wiele tekstów z tego kopiarza (inwentarz kościoła, świadczący jak bogate było wyposażenie tej wiejskiej świątyni, statuty mansjonarzy, etc.) wydał M. Sokołowski. Na skutek ograniczonego miejsca przeznaczonego na edycję, tekst nie został zaopatrzony przypisami, jak również nie wydano z marginesów boczków, w dużej części uszkodzonych.

W XV i XVI w. powstawały w Polsce przy kościołach parafialnych, erygowane kanonicznie, prepozytury $\mathrm{z}$ mansjonariami. Wzorowane były na kapitułach katedralnych i na kolegiatach. Miały za cel podniesienie duszpasterstwa parafialnego, zaniedbanego przez rozluźnienie dyscypliny wśród duchowieństwa, kumulację beneficjów i spekulacje nimi. Jednak przy ich powstawaniu odgrywały też dużą rolę ambicje fundatorów ${ }^{4}$. Prepozytury nawiązywały do życia kanonicznego. Składały się z prepozyta i co najmniej czterech mansjonarzy. Były fundowane najczęściej dla śpiewania $w$ chórze, w dzień i w nocy, godzin kanonicznych ku czci NMP. Formalnym fundatorem prepozytury w Książnicach Wielkich był klasztor tyniecki, zaś inicjatorem i faktycznym fundatorem był dotychczasowy proboszcz Mikołaj z Koprzywnicy, zwany też $z$ Szadka ${ }^{5}$. Probostwo w tym kościele odstapił mu w r. 1477 wybitny dekretysta Uniwersytetu Krakowskiego prawdopodobnie krewniak, Jakub z Szadka, który też przyjął go do herbu Wieniawa i zatrudniał w swojej kancelarii. W r. 1475/1476 Mikołaj wpisał się na Uniwersytet Krakowski. Na podstawie zapiski, znajdującej się w kopiarzu, ale pochodzącej dopiero z XVII w., miał być bakałarzem dekretów. W latach 1489-1491 odbył pielgrzymkę do Jerozolimy, Rzymu, Bari, Akwizgranu i innych miejsc w Europie, odwiedzanych przez pątników.

Był altarystą przy ołtarzu św. Antoniego w katedrze na Wawelu. Gdy obejmował kościół i plebanię w Książnicach Wielkich po swoich poprzednikach (a jednym z nich był późniejszy biskup Grzegorz z Sanoka), wszystko zastał $\mathrm{w}$ ruinie, kościół spalił się. Jako proboszcz dokonał dużego dzieła. $Z$ funduszy zdobytych gravissimis laboribus et sudoribus et ex serviciis suis zbudował nowy, drewniany kościół, poświęcony w r. 1485 i całkowicie go wyposażył. Własnym też sumptem ufundował i darował wspaniały poliptyk, dzwony, krzyże, kielichy, ornaty, choraggwie, księgi, etc. Kopia bardzo szcze-

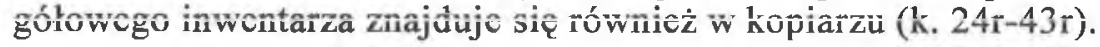

${ }^{4}$ Podstawowe wiadomości o kolegiach mansjonarzy zob.: J. S z y mań ski, Poczqtki prepozytur $w$ diecezji krakowskiej, „Roczniki Teologiczno-kanoniczne”, t. 9:1962, z. 1, s. 65-76; J. N o w a c k i, Archidiecezja poznańska w granicach historycznych i jej ustrój, Poznań 1964, s. 730 i in.; S. Litak, Struktura i fundacje parafii W: Kościót w Polsce, t. 2, Kraków 1969, s. $328 \mathrm{i}$ in.

${ }^{5}$ L. Hajd u ki ew icz, Mikołaj z Koprzywnicy, Polski Słownik Biograficzny, t. 21, Kraków 1976, s. 114-115. 
Przywilej erekcyjny prepozytury z mansjonarią w Książnicach Wielkich przy kościele św. Trójcy, Wniebowzięcia NMP i św. Stefana węgierskiego, wystawiony został przez biskupa krakowskiego Jana Konarskiego 17 maja 1508 w Krakowie, w czasie trwania kapituły generalnej, zbierającej się co roku około święta św. Stanisława. W kopiarzu dokument ten przepisany został na k. 50r-62r. Po krótkiej arendze i narracji inserowany został w całości akt fundacji prepozytury z mansjonarią w Książnicach Wielkich (k. 50r-62r). Wystawiono go w Tyńcu 16 maja 1508 (tj. przed dniem wystawienia dokumentu biskupiego) przez Jana Piotrowskiego i konwent benedyktyński, reprezentowany przez Stanisława przeora, Pawła podprzeora i kustosza, Mikołaja przełożonego infirmerii, Pawła i Stanisława skarbników oraz Macieja włodarza. Książnice były bowiem wsią należącą do opactwa benedyktynów w Tyńcu. Zatem w kościele tutejszym benedyktyni mieli prawo prezenty i patronatu. Akt fundacyjny ogłasza fakt utworzenia w Książnicach Wielkich przy kościele św. Trójcy, NMP i św. Stefana, prepozytury z mansjonarią złożoną z czterech mansjonarzy albo wikariuszy (zwanych też czasem subcanonici) oraz rektora szkoły. Dotąd w Ksiazznicach Wielkich był proboszcz i dwóch wikariuszy. Zarówno prepozyt jak i mansjonarze byli dożywotni (perpetui). Mogli być odwołani tylko w wypadku zaniedbań i skandali, czyli nie przestrzegania statutów, które uchwalali wspólnie prepozyt i mansjonarze. Statuty też sa przepisane w kopiarzu (k. 13r-24r). Ani prepozyt ani mansjonarze nie mogli kumulować i zamieniać swoich beneficjów. Ponadto byli zobowiązani do stałego przebywania przy kościele (mansio, stąd pochodzi ich nazwa). Przepisy ściśle regulowały dozwolony czas absencji. Prepozyt tracił urząd, gdy jego nieobecność trwała cztery miesiące.

Mansjonarze, powoływani przez prepozyta, poza zwykłymi duszpasterskimi obowiązkami, w dzień i w nocy śpiewali godziny kanoniczne o NMP i odprawiali mszę św. Salve Sancta Parens, głosili kazania, każdy w swoim tygodniu, tzw. hebdomadarius. Również ściśle zostało określone to co należało do powinności prepozyta wybieranego przez mansjonarzy. W wyliczone święta miał odprawiać przy udziale mansjonarzy oficja, msze św. Był też zobowiązany do wygłaszania kazań co najmniej cztery razy w roku. W ważne święta dawał poczęstunek (prandium) mansjonarzom, aby ci tym gorliwiej pełnili służbę w kościele. Był też zobowiązany płacić wszystkie kontrybucje nakładane przez ordynariusza, czy inne władze oraz bronić interesów mansjonarzy, występować w sprawach spornych, etc.

Wśród mansjonarzy jeden był seniorem precentorem, drugi zaś zakrystianinem, który miał w swojej pieczy przedmioty kultu, bibliotekę, znajdujące się w kościele. Co roku we wtorek wielkanocny przeprowadzał on razem z prepozytem na podstawie sporządzonych spisów inwentarzowych kontrolę mienia i wyposażenia kościelnego, kupował świece, wino. Przy kościele istniało też bractwo, którego seniorzy uczestniczyli w działalności prepozytury.

W ordynacji zostało bardzo dokładnie przedstawione bogate uposażenie, dochody i wpływy dla prepozyta (dziesięciny z Książnic Małych, Majkowic, z dwóch zagród w Książnicach Wielkich, karczma w Książnicach Wielkich, 
sadzawki, etc.), mansjonarzy (dziesięciny w Modrzanach, Zysławicach, Jankowicach, Barczkowie, Wroczkowie, Macieczynie, z karczmy w Książnicach Wielkich, etc.) i rektora szkoły. Zadbano o bezpieczne przechowywanie pieniędzy w skrzynkach sub tribus seris. Mansjonarze mieszkali najpierw w dwóch domach, potem miał być zbudowany jeden dla wszystkich. Korzystali ze wspólnego stołu. Zabezpieczone zostały fundusze na budowę kościoła i domu mansjonarzy.

W zakończeniu ordynacji opat zwraca się do biskupa ordynariusza z prośbą o zamianę probostwa na prepozyturę, o zatwierdzenie wszystkich punktów i klauzul oraz o instytucję Mikołaja z Koprzywnicy na urząd prepozyta. Biskup w drugiej części transumptu ogłosił, że za zgodą dotychczasowego proboszcza Mikołaja z Koprzywnicy oraz kapituły krakowskiej, wygasł tytuł kościoła książnickiego plebanatus, a utworzona została prepozytura, składająca się z prepozyta, czterech mansjonarzy i rektora szkoły. Mansjonarze zostali powołani ad cantandum cursum sive omnes et singulas horas Beate Marie Virginis una cum missa Salve Sancta Parens przy pełnieniu dotychczasowych obowiązków duszpasterskich wikariuszy. Zatwierdził w całości ordynację, powtarzając jej punkty i klauzule. Na pierwszego prepozyta powołał dotychczasowego proboszcza Mikołaja z Koprzywnicy, tylko jego nie obowiązywał zakaz kumulacji beneficjów i stałe zamieszkanie w Książnicach Wielkich. Nadal przebywał on w Krakowie. Następnie ogłosił zapis testamentowy Mikołaja z Koprzywnicy na kościół w Książnicach Wielkich. Na rzecz prepozytury legował on całe swoje mienie. Były to dary, które przechowywane były w kościele: krzyże, kielichy, ornaty, księgi, etc. Ponadto cały dobytek żywy i martwy: konie, bydło, drób, zboże, znajdujące się w spichrzu, w zasiewach i w dziesięcinach, narzędzia rolnicze, wozy (także nakryty płótnem), przedmioty i naczynia kuchenne, zastawa stołowa. Odchodzący prepozyt wszystko to miał zostawiać nieuszczuplone następcy.

Nakazana została też pamięć o fundatorze i benefaktorze. W każdej mszy św. Salve Sancta Parens wspomniany miał być Mikołaj. Raz zaś w tygodniu odprawiano mszę św. w jego intencji, a do każdego kazania była dołączana jego komemoracja. Również w rocznicę śmierci i nazajutrz odprawiano mszę św. za jego duszę. Jako świadkowie wystapili w transumpcie członkowie kapituły krakowskiej: Jan Latalski prepozyt, Mikołaj Bedleński scholastyk, Piotr Wapowski z Radochoniec kantor, Andrzej Rabsztyński, Zygmunt Targowicki, Mikołaj Czepiel, Jan Rzeszowski?, Maciej z Szydłowa, Jan Salomon, Jan z Oświęcimia, Jan Karnkowski, Maciej Grodzicki, Tomasz Rożnowski, Jakub Staszkowski, Ian Jakubowski, Maciej Raciąż, Jakub Ercieszowski prałaci i kanonicy oraz notariusze: Marcin ze Zbyk, Augustyn z Baruchowa, Jan Jastrzębski. Notariuszem tego aktu erekcyjnego był Stanisław syn Baltazara z Sandomierza.

Mansjonarze w święto Wniebowzięcia NMP w r. 1508 zaczęli po raz pierwszy śpiewać cursum seu horas de BMV. Prepozyturę zatwierdził papież Leon X bullą wydaną w Rzymie w r. 1512 (k. 62r-63r). Utworzenie prepozytury w Książnicach Wielkich musiało zrobić duże wrażenie na współcze- 
snych, było liczącym się wydarzeniem, skoro Decjusz w swoim dziele $D e$ Sigismundi regis temporibus zapisał: in Maiori Xiansznicze prepositura et quatuor mansionarii ex parochiali ibidem ecclesia abbatis conventusque Thinicensis patronorum assensu Nicolao de Coprzywnicza rem promovente et Ioanne Conario episcopo Cracoviensi confirmante erecta et fundata est ${ }^{6}$.

Prepozytura w formie erygowanej w r. 1508 zasadniczo przetrwała do r. 1809. Na skutek zmniejszenia się uposażenia i zubożenia parafii pozostało wówczas tylko dwóch mansjonarzy, wikariuszy, zwolnionych ze śpiewania w chórze godzin o Matce Boskiej ${ }^{7}$.

${ }^{6}$ J. L. D e cius, De Sigismundi regis temporibus liber, wyd. W. Czermak, Biblioteka Pisarzy Polskich, Kraków 1901, s. 26.

J. G u r d a, Ksiqżnice Wielkie, Zarys dziejów, Kielce 1992, s. 27. 


\section{PRIVILEGIUM SEU ERECTIO PREPOSITURE CUM MANSIONARIIS ECCLESIE IN MAIORI XYASNICZE}

In nomine Domini Amen. Ad rei memoriam sempiternam Joannes de Conari Dei et Apostolice Sedis gratia episcopus ecclesie Cracouiensis. Cum universorum mortalium ad id frui debent conatus et intencio iugiterque aspirandum et advertendum est omnibus in presenti miseriarum valle constitutis, ut illustrissimam et gloriosissimam Genitricem Dei et hominis Mariam Virginem angelos vincentem puritate, sanctos superantem claritate, venerentur obsequiis et continuum. Illi impendant honoris et servitutis famulatum, cuius sacratissimus uterus largo Spiritus Sancti imbre perfusus Divinitatis utraque natura salva homini perdito redempcionem afferens civitatis superne Ierusalem aditum patefecit; et cuius integritas corrupcionis nostre culpam excusat cuiusque humilitas vanitati nostre meretur veniam, charitas multitudinem pecatorum cooperit et intercessio ad visionem speculi Benedicte Trinitatis perducit, libet nobis insuper pya vota supplicium nostris confirmare desideriis, ut pro hiis, que seminarent in terris perhennem gloriam, inter sanctorum mansiones consequi mereantur in celis.

Proinde significamus tenore presencium quibus expedit universis presentibus et futuris presencium noticiam habituris, quomodo debita consideracione attendentes, quod dudum ecclesia parochialis in villa Maiori Xansznycze nostre diocesis ad laudem et gloriam Omnipotentis Dei sub titulo benedicte et individue Trinitatis Virginisque Sancte Marie Assumpcionis necnon sancti Stephani regis Vngarie ac omnium sanctorum patronorum eiusdem ecclesie in villa Maiori Xansznycze site fundata et erecta nonnullis bonis mobilibus et immobilibus ac decimis proventibusque et reditibus ex singulari liberalitate venerabilium et religiosorum fratrum abbatis et conventus monasterii Tiniciensis, illius patronorum et collatorum dotata et fulcita existens, non tamen quantum meretur et loci illius requirit amenitas, divinis laudibus honoratur, specialis devocionis nostre permoti affectu censuimus illam ad peticionem eorundem abbatis et fratrum conventus monasterii memorati Tiniciensis tanquam patronorum ecclesie ipsius extollere prerogativis novis, ut in ea Deus altissimus laudetur et Virgo ipsa gloriosissima Maria Genitrix Domini nostri Ihesu Christi veneretur abundancius cultusque divinus salubrius fervenciusque et devocius perseveret, quanto persone ecclesiastice in numero plures constitute illinc fuerint et aucte; presertim, ut in eadem ecclesia parochiaí Xansznyczensi resonet et concrepet iaus ipsa divina et singulari ministerio officium Beatissime eiusdem Dei Genitricis Virginis Marie in cantu expleatur ad honorem Omnipotentis Dei et ipsius Genitricis benedicte [k. 50v] Marie, preposituram et quatuor mansionarios actu presbiteros perpetuos et quintum rectorem schole manualem de ipsa Virgine gloriosa diurnas et nocturnas horas in cantu expleturos de consilio et assensu venerabilis capituli ecclesie nostre cathedralis Cracouiensis fundandos, 
creandos et erigendos duximus pro votis et desideriis ipsorum abbatis et conventus monasterii predicti necnon honorabilis Nicolai de Koprzywnycza rectoris illius ecclesie moderni et huius rei cooperatoris ac illorum peticionibus huiusmodi iustis et racioni consonis in certis patentibus literis in pargameno scriptis sigillisque ipsorum abbatis et conventus appensis roboratis nobisque pro maiori horum subsistencia exibitis et oblatis contentis non minus allecti et annuentes, quarum quidem literarum tenor sequitur in hunc modum.

In nomine Domini Amen. Nos frater Ioannes Pyotrowszky divina paciencia abbas, Stanislaus prior, Paulus subprior et custos, Nicolaus prepositus infirmorum, Paulus et Stanislaus tesaurarii, Mathias procurator totusque conventus monasterii Thiniciensis ordinis sancti Benedicti diocesis Cracouiensis collatores et patroni ecclesie parochialis tunc benedicte et individue Trinitatis Virginisque sancte Marie Assumpcionis necnon sancti Sthephani regis Vngarie ac omnium sanctorum patronorum eiusdem ecclesie in villa nostra Maiori Xyansznycze site, inter affectuosissima cordis nostri vota ad hec potissimum nostra humilis ac devota inclinatur ac suspirat devocio, ut ea propensiori studio prosequamur, que divine laudis amplitudinem et humane salutis premium adicerent sempiternum. Quatenus celestia terrenis comparantes illas beatas et immortales opes adipisci mereamur, quas nec rubigo absumit nec tinea demollitur, hinc est ut ecclesia eadem benedicte Trinitatis Virginisque Marie Assumpcionis, sancti Stephani regis Vngarie ac omnium sanctorum iuris patronatus et collacionis nostre in uberiori laudum cumulo pro summi Dei maiestate sanctorumque christifidelium successu temporis nostrorum felici semper auspicio adaugeretur resque ipse, que in ipsius pyos usus pro eorundem perpetua continuacione ac subsistencia prestarentur, solide ac firme literarum testimonio in posterum subsistere possint. Ob id tenore presentium notum facimus universis presentibus et futuris et presentium noticiam habituris, quomodo provida ac matura deliberatione animo revolventes ecclesiam nostram prefatam in Maiori Xyanycze dono Dei ac plurimorum fidelium inter alias ecclesias non [k. 51r] minorem gaudere, insigniri ac dotari munificencia ipsique sumptuose ac decenter ornate, dotate et fundate populoseque existenti quottidiana suffragia ac beneficia plurimorum non deesse, quorum usus eciam pro maiori quadam et eminenciori institucione sufficere possit ac demum humili supplicacioni honorabilis domini Nicolai de Koprzywnycza altariste ecclesie cathedralis Cracouiensis peregrini Ierosolimitani ac eiusdem ecclesie in Maiori Xyansznycze rectoris annuendo, de cuius eciam sciencia et unanimi voto ac deliberacione nostra nobis capitulariter congregatis presentem ordinacionem et erectionem mansionariorum infrascriptorum instituere deliberavimus et decrevimus, prospectum nichilominus habentes ad ipsius ecclesie fundum ac certos proventus ac proinde in laudem Dei sueque caste Parentis Virginis Marie sanctorumque omnium gloria uberiori ipsam ecclesiam predictam subsiniari[?] titulo elucere et insigniri cupientes, eandem per reverendissimum in Christo patrem et dominum domi- 
num Joannem Dei gratia episcopum Cracouiensem denuo erigendam et per suam paternitatem reverendissimam titulo plebanatus, quo hactenus gaudebat, extincto, suppresso et abrogato denuo creandum et erigendum decrevimus, constituimus et simpliciter deliberavimus, sic ut pro regimine eiusdem ecclesie ac cura animarum prepositus a modo creetur, nominetur et vocetur, qui sit perpetuus et mansionarii seu vicarii eciam sint perpetui, quatuor in numero, quintus rector seu magister schole, qui sit manualis ad voluntatem prepositi. Qui quatuor mansionarii actu presbiteri valentes vita, moribus et convictu honesti circa eandem ecclesiam per ipsum prepositum instituantur et locentur ad decantandum cursum sive omnes et singulas horas beate Marie Virginis una cum missa Salve Sancta Parens, que quolibet die loco manerie cantabitur. Ipse denique prepositus institutus, habebit omnem potestatem et auctoritatem predictos mansionarios seu vicarios vocandi, instituendi et malos iuxta eorum demerita, excessus et scandala, protervos, inobedientes et circa obsequium ecclesie negligentes statutisque eisdem dandis contravenientes [k. 51v] una nobiscum, abbate videlicet Thiniciensi alienandi, removendi et eos reiciendi. De aliisque prepositus per se honestioribus eisdem succedendis instituendi similiter habebit auctoritatem. Quem prepositum predicti quatuor mansionarii seu vicarii ex se eligent tempore cessus vel decessus et nos abbas pro tempore existens cum conventu nostro monasterii Thiniciensis consentire debebimus in eundem electum per mansionarios et domino episcopo Cracoviensi presentabimus per literas nostras pro institucione seu confirmacione. Et predicti mansionarii si sint, quod absit, rebelles vel qui invenirentur inobedientes, qui nollent exequi mandata prepositi aut illius quem prepositus constituerit loco sui in seniorem, (qui senior vocetur precentor), vel eciam qui nollent exequi statuta domus aut qui essent bibuli, continui tabernatores vel eciam scandalosi meretricarii, contenciosi aut ad officia sua negligentes, plus soliciti de visitandis tabernis, mulieribus quam de ecclesia, si post binam admonicionem emendari recusarint, extunc in loca eorum tanquam rebellium alii substitui per prepositum debent. Item predictos mansionarios rebelles, discordes et scandalosos, recepto testimonio sufficienti trium de ecclesia presbiterorum vel eciam aliarum fidedignarum personarum secularium prepositus una nobiscum, abbate videlicet Thiniciensi pro tempore existenti, licenciabunt et alium vel alios prepositus per se vocabit et instituet. Item prepositus cum mansionariis sint monoculi, ita quod nullum beneficium [nadpisane curatum] aliud audeat quis habere cum prepositura aut mansionaria preter dominum Nicolaum de Koprzywnycza modernum rectorem et cooperatorem harum mansionariarum specialemque benefactorem eiusdem ecclesie in eadem Maiori Xyansznycze, qui poterit plura beneficia habere cum eadem prepositura solum ad vitam suam, siue eciam cessum vel decessum. Cum quo domino Nicolao dispensamus pro hac vice, cum aliis autem successoribus nolumus dispensare. [Si] qui illud habuerit, non sit idoneus ad illius suscepcionem et vocacionem, et si habuerit occulte vel manifeste vel eciam per errorem, eo facto non sit idoneus et privetur ea. Quibus mansionariis 
[k. 52r] prepositus una cum mansionariis eisdem dabit et instituet statuta, secundum que vivere et regere se tam in ecclesia quam in domo negligentesque scandalosos ac excedentes punire debebunt. Que eciam statuta quilibet prepositus et mansionarius circa recepcionem et institucionem observare et manutenere cum effectu iurabit secundum ordinacionem et disposicionem presentis privilegii ac statutorum per prepositum et mansionarios predictos conficiendorum. Prepositus eciam magistrum seu rectorem schole presentabit et vocabit, quem tenebit ad voluntatem suam. Qui magister seu rector schole esset bonus ad hoc regimen seu officium, discretus, idoneus, obediens, concors et humilis. Qui iuvabit et tenebitur cantare in choro omnes horas de Domina et Missam Salve Sancta Parens cum predictis mansionariis. Cantum vero choralem ab antiquo consvetum et cantatum predictus magister cum scholaribus cantabit, qui cantus permaneat integer, prout est et erat ab antiquo institutum. Qui magister schole a preposito habebit tres marcas peccuniarum pro salario suo de taberna prepositi in Maiori Xyasznycze. Qui eciam magister seu rector schole habebit ascensum ad predictas mansionarias, si tamen erit idoneus et abilis ad hoc officium et quod infra unum annum promoveatur in presbiterum. Qui magister schole habebit eciam pulsales et a Salve et a Cruce et a funeralibus, sed tamen a pulsalibus habeat zacristianus medietatem pulsalium et magister aliam medietatem cum Salve et a Cruce. Prepositus una cum mansionariis et magistro schole nullus audeat intrare ecclesiam aut chorum infra divina officia sine superpelicio ad decantandum cursum beate Marie Virginis aut alium cantum coralem, sed semper incedant superpelliciati et in biretis sacerdotalibus, non laicorum, quod absit, sub pena excomunicacionis et eterna dampnacione. Quem prepositum predicti mansionarii habebunt in reverencia et honore tanquam suum prelatum, cui debebunt in omnibus licitis et honestis obedire et populo [k. 52v] revereri. Item vicarius seu mansionarius cantans missam de Beata Maria sit solutus dumtaxat a cura ecclesie, sed mansionarius, qui sequi debebit sequenti septimana ad cantum prefate misse, ebdomadarius vocabitur. Et idem ebdomadarius tenebitur visitare infirmos, pueros baptisare, introducere, cittare et alia officia, que pertinent et spectant ad ebdomadarium, supplere et in choro intonare secundum consvetudinem mansionariorum ecclesie cathedralis Cracouiensis. Item ipsi mansionarii seu vicarii, quos prepositus instituet seu confirmabit in ipsa ecclesia, predicabunt quilibet per se sua ebdomada et in vicibus suarum ebdomadarum pronuntiando cum diligencia et fervore verbum Dei, cui cum diligencia intendent et insistent studio diligenti. Et tamen in necessitate omnes gerant curam infirmorum, cui gerende erunt obligati. Et quod ipsi mansionarii in solidum alia omnia officia et servicia ecclesie predicte, que ab antiquo per plebanum et vicarios duos implebantur, debebunt et tenebuntur sine diminucione adimplere. Predicti itaque mansionarii quatuor seu vicarii per semetipsos gerent labores omnes ad ecclesiam et animarum curam pertinentes, quemadmodum vicarii duo cum plebano, qui antedicte ecclesie inserviebant gerere soliti erant, et ordinem inter se habeant in administracione om- 
nium officiorum ecclesie, ita quod unus alio non plus oneretur, et unius quam alterius non sit melior condicio, nisi forte infirmitas aliquem impedierit aut ex causa racionabili aliquem peregrinari seu ad causas suas arduas disponendas abire contigerit. Extunc ad id habito consensu prepositi pro tempore existentis poterit alterum idoneum et valentem virum substituere ad salarii sui defalcacionem; et absencia sua duas septimanas non excedat, excepto quod talis necessitas esset, quod tempus longius requireret, extunc prepositus accepta de hoc plena informacione poterit diucius dispensare cum eodem, ita tamen quod in nullo casu licencia quatuor menses excedat. Quibus evolutis, si non redierit, volumus candem vacare et tunc poterit et debebit alter in locum suum per prepositum [k. 53r] surrogari. Idem eciam volumus habere de preposito: si absens fuerit per quatuor menses, vaccabit prepositura. Et volumus, ut alius prepositus per predictos mansionarios eligatur in locum suum et presentetur nobis abbati et conventui monasterii nostri Thiniciensis et nos domino episcopo Cracouiensi pro tempore existenti per litteras nostras remittemus pro confirmacione et institucione ad predictam preposituram. Prepositus eciam tenebitur ad omnia festa mobilia tenere et cantare omnia officia, sicut in die sancte Trinitatis, Corporis Cristi etc. et eciam ad omnia festa Beate Marie Virginis necnon in festo Dedicacionis ecclesie, ad omnia festa Apostolorum sanctorumque Stanislai, Adalberti, ad sancti Stephani regis Vngarie patroni eiusdem ecclesie, Martini, Nicolai, Laurencii, Iohannis Baptiste, Michaelis, Omnium Sanctorum, eciam in dominica Ramispalmarum, feriis magnis quinta, sexta et sabbato et consequenter diebus Pasche sicut primas, vesperas et secundas, matutinum et missam summam, excepta infirmitate aut absencia sua pro tunc, quando esset absens in festo ecclesie. Et duo ex mansionariis tenebuntur ei assistere et ministrare, unus ewangelio et alius epistola. Et eciam alius, prout est mos et consvetudo in ecclesiis collegiatis, omnes quatuor mansionarii seu vicarii tenebuntur ei assistere, quando cantabit capitula et oraciones tam in matutinis quam in vesperis. Prepositus eciam faciet sermonem ad populum ad minus quater in anno, ad quod eciam sit obligatus. Quando vero contigerit preposituram vaccare per cessum vel decessum, illi quatuor mansionarii primo cantata missa de Sancto Spiritu et per quemlibet lecta, convenientes ibidem in ecclesia post missas lorum et post alia omnia officia divina ante summum altare, invocato prius Spiritu Sancto, procedent in nomine Domini ad electionem canonicam, perlecto prius privilegio et statutis de electione prepositi. Et eligant inter se unum ex quatuor predictis mansionariis in prepositum. virum idoneum, valentem Deo, ecclesie et populo [k. 53v] Dei, qui esset utilis Deo per bona exempla in vita et moribus. Si omnes tres predicti mansionarii concordabunt in unum, laudandus est Deus. Si unus erit discors, stabit electio in duobus et illum electum predicti mansionarii representabunt nobis abbati et conventui monasterii nostri Thiniciensis. In quem electum nos abbas, pro tempore existens cum conventu nostro debebimus consentire et domino episcopo Cracouiensi per litteras nostras presentacionis presentare pro confirmacione et institucione 
eiusdem electi prepositi. Casu vero quo dicti mansionarii circa eleccionem essent divisi per discordiam votorum in duas partes equaliter, extunc ille erit prepositus, pro quo abbas Thiniciensis pro tempore existens ex illis in dicta discordia electis gratifficaverit.

Et quia nemo tenetur propriis stipendiis militare et qui altari servit de altare vivat spiritualiaque sine temporibus non recte subsistunt, equum et iustum censemus, ut ipse prepositus proventus, obvenciones ex solito spectare consvetas percipiat et usufruatur. Primo igitur habeat pro fundo sue prepositure predium ex antiquo plebanale cum agris et pratis omnibus ad ipsum predium plebani pertinentibus ac parte gay per venerabiles viros de consensu parcium, scilicet reverendi patris domini abbatis et sui conventus ac honorabilis domini Nicolai plebani in eadem Xyansznycze auctoritate reverendi patris domini episcopi Cracoviensis et sui venerabilis capituli commissarios pro plebano ex antiquo emensurati, necnon et rubetis alias Rzechthy et lacum sub villa Maczyczyna, prout antecessores sui cum decimis et cultura sua hactenus recipiebant et habebant. Primo decimam in villa monasterii nostri in Minori Xyansznycze, item aliam decimam in villa militari nobilis domini Przeczeszky in Moykowycze, duas ortulanias in Maiori Xyansznycze cum decimis post easdem ortulanias. Item prepositus habeat unam partem offertorii, duas mansionarii et quartam rector seu magister schole. Prepositus habeat tabernam in Maiori Xyansznycze cum piscina, que piscina iacet [k. 54r] penes eandem tabernam in Maiori Xyansznicze, que piscina data est per nos abbatem et conventum monasterii Thiniciensi preposito. De qua taberna hereditaria solvuntur quatuor marce peccuniarum annuatim pro festo sancte Marie Nativitatis ab antiquo secundum privilegium eiusdem tabernatoris, de quibus quatuor marcis provenientibus ex eadem taberna solvet prepositus rectori seu magistro schole tres marcas racione servicii sui et laborum suorum. Residuum tollet prepositus de eadem taberna, pro se videlicet quartam marcam. Item adhuc prepositus habeat aliam piscinam, que iacet penes agrum Oszthrow post tabernam prepositi, que nunc iacet deserta. Item alii proventus et speciales pro mansionariis seu vicariis. Qui vicarii seu mansionarii habebunt decimas in villis in eadem parochia Xyansznyciensi consistentes. Et primo in nostra villa Modrzani, Dzczyslaslavycze, Jankowycze, Barczkow, Wroczkow, Maczyczyna et decimam post tabernam prepositi in Maiori Xyasznycze pro leguminibus pro domo eorundem mansionariorum. Item columbacionem totam peccunialem post totam parochiam cum denario sancti Petri, de qua columbacione solvent mansionarii petronales, videlicet quatuordecim scotos cum uno grosso, quittancie habebunt, quod divident inter se equaliter sine iniuria uniuscuiusque. Item columbacio, que datur post villas in provisionibus, tota cedat pro mansionariis in commune pro eorum domo seu coquina. Harum autem provisionum de columbacione magister schole habeat eciam quartam partem de decimis eorum mansionariorum. Provideant eis provisiones alias pro domo et coquina pro expensis eorum. Habeant eciam predicti mansionarii duas piscinulas, que iacent post horreum plebani seu 
prepositi, pro eorum mensa. Item missas votivas tricesimas lectas vicarii seu mansionarii habebunt soli per se, dividendo inter se equaliter sine iniuria uniuscuiusque. Item vigilias, votivas, missas tricesimas cantatas magister schole, qui cum eisdem mansionariis cantabit quartam partem cum eis [k. 54v] participabit, prout fuit ex antiqua consvetudine. Spolium, sicut equi, boves vel aliqua alia sicut peccora, pecudes vel eciam fruges aut pannus, horum omnium prepositus primam partem percipiat, duas mansionarii et quarta pars cedat pro fabrica ecclesie. Que quarta pars servetur in cisticula ecclesie cum peccunis, que cedent de tabula et de vaccis ecclesie. Et sint predicte peccunie sub tribus seris. Et sic hoc spolium ad quatuor partes dividetur prout supra. Item a sepultura, qui sepelliuntur in ecclesia, aliquando datur pro fabrica ecclesie una marca peccuniarum vel eciam racione marce peccuniarum datur equus vel bos vel aliqua peccora, pecudes vel fruges vel aliquod tale. Hec omnia commitantur pro fabrica ecclesie et serventur in cisticula prout supra tactum est. Prepositus tenebitur eciam eisdem vicariis seu mansionariis dare reffectionem seu prandium ad omnia festa infrascripta sicut in vigilia Nativitatis Domini, ipso die Nativitatis Christi, sanctorum Stephani, Johannis, Innocentium, Circumcisionis et Epiphanie Domini, per omnia tria festa Pasche, eciam Ascensionis Domini, per omnia festa tria Pentecostes, item ad omnia festa celebrata a populo Beate Marie Virginis, Omnium Sanctorum et in festo Dedicacionis ecclesie, eciam in festo Corporis Cristi, ut predicti mansionarii sint hiis diebus sacris eo diligenciores et fervenciores ad cultum divinum, et quod non occupent se aliis extraneis, nisi circa divina officia. Prepositus eciam tenebitur tenere et servare equum pro mansionariis ad equitandum cum Communione ad infirmos tociens quociens fuerit neccesse. Prepositus eciam tenebitur solvere et expedire contribucionem totam per diocesanum institutam aut quemcumque alium pro quocumque negocio. Prepositus tenebitur mansionarios tueri, deffendere pro iniuriis decimarum eorundem mansionariorum suis impensis iuxta suum posse, cum adiutorio tamen eorundem mansionariorum, ut predicti mansionarii non negligant divina officia [k. 55r] discurrentes hinc et inde ad lites seu ad iurgia. Prepositus faciet ordinacionem de tezauro ecclesie et aliis omnibus rebus, que sunt ecclesie. Primo instituet cum mansionariis unum ex eisdem quatuor mansionariis zacristianum, qui custodiat, servet, regat et gubernet omnes res ecclesie, sicut calices, cruces, casulas, libros et alias omnes res et ornamenta ecclesie predicte, qui ad hoc officium magis esset habilis et idoneus. Qui zacristianus feria tercia Pasche semel in anno faciet racionem de predictis rebus ecclesie preposito et aliis confratribus suis mansionariis, adiungendo eciam quatuor fratres seniores de fraternitate fratrum eiusdem ecclesie. Qui prepositus cum mansionariis prius conscribent omnes res ecclesie et facient inventarium omnium rerum predicte ecclesie, quod inventarium prepositus cum mansionariis tradent et dabunt zacristiano cum aliis rebus ecclesie. De quo inventario faciet racionem predictus zacristianus quolibet anno. Et prepositus habeat circa se aliud inventarium. Ceram, vinum pro ecclesia emet et compa- 
rabit zacristianus ecclesie ex tabula et peccuniis vaccarum, que peccunie provenientes ex tabula et vaccis serventur in una cisticula, que cisticula claudatur tribus seris, a qua cisticula habeantur tres claves. Primam habeat prepositus, secundam zacristianus et terciam vitricus ecclesie aut frater unus ex quatuor senioribus fratrum de fraternitate. Residue autem peccunie ex eadem tabula et vaccis provenientes de eadem cisticula convertentur pro fabrica ecclesie. Volumus preterea, ut dicti quatuor mansionarii ad tempus duo in una domo commaneant et alii duo in altera domo viccariorum et quod simul omnes quatuor comedant in una domo et circa unam tabulam usque ad edificacionem nove domus, in qua commanebunt simul omnes quatuor predicti mansionarii seu vicarii camerasque secundum prioritatem vocacionis habeant ex ordine. Vivent sub statutis concorditer et discordes inter se puniantur iuxta predicta statuta per [k. 55v] ipsos cum preposito confficienda. Et prepositus instituet eis ex illis quatuor mansionariis unum in seniorem, qui vocetur precentor, prout supra tactum est, qui erit magis ex illis idoneus ad hoc officium ad dirigendos eosdem mansionarios et magistrum schole in choro, cantu, in ecclesia tam eciam in domo. Qui senior seu precentor prefferetur eisdem honestate et loco. Quos mansionarios predictus senior corriget de moribus et erroribus malis tam in ecclesia quam in domo. Et si essent aliqui rebelles aut inobedientes, defferet eos precentor preposito et prepositus faciet cum eis secundum demerita eorum, secundum privilegii ordinacionem et disposicionem aut secundum statuta eorum. Item quilibet intrans domum seu mansionariam vicariius seu mansionariius dabit unum fertonem introitales, que peccunie introitalium serventur ad cisticulam, que cisticula domus specialis habeatur et servetur in zacristia ecclesie. Ad quam cisticulam sint due sere et due claves. Unam clavem habeat precentor et aliam prepositus domus seu dispensator, que peccunie de eisdem introitalibus serventur et convertentur pro fabrica domus predictorum mansionariorum. Item quilibet eciam vicarius seu mansionarius contribuet et dabit unum grossum ad quelibet quatuor tempora pro reformacione seu fabrica domus, que peccunie eciam conserventur in cisticula domus pro predicta fabrica predicte domus mansionariorum. Et si aliquis eorum esset negligens in solvendo, superintendat precentor, ut quilibet solvat sine dilacione, et recipiet precentor de sua porcione tempore distribucionis aut divisionis peccuniarum. Item si aliquis vel aliqui mansionariorum predictorum senio vel infirmitate longa detenti fuerint, per substitutos idoneos servicia et officia huiusmodi complere et peragere debebunt et erunt astricti. Et si eosdem substitutos dare neglexerit, prepositus existens pro tempore [k. 55v], debebit alium mansionarium loco illius vel illorum instituere vel locare, ne propter eorum longam infirmitatem negligencia committeretur in divinis officiis. Et prepositus cum aliis mansionariis tempestive providebunt de illo infirmo secundum possibilitatem et facultatem eorum et condicionem illius infirmi. Qui quidem mansionarii tempore vacacionis prepositure habebunt curam et diligenciam de omnibus rebus tam spiritualibus quam temporalibus eiusdem prepositure usque ad institucionem 
novi prepositi, cui preposito novo predicti mansionarii tenebuntur facere racionem de omnibus rebus per eosdem receptis et perceptis. Et idem prepositus novus presentabit et dabit alium mansionarium quartum in locum suum, videlicet rectorem seu magistrum schole, si erit ad hoc abilis et idoneus et ut promovetur infra unum annum in presbiterum. Item volumus eciam, quod si et in quantum fuerit predictus prepositus negligens circa ecclesiam in officio divino aut eciam in dote prepositure sue circa labores domesticos aut prodigus aut scandalosus esset, ita quod bona ecclesie et in dote prepositure per suam inadvertenciam aut incurabilitatem anichilaret, dilapidaret vel diminueret, non augmentando sed ea bona diminuendo, ille prepositus per dominum abbatem pro tempore existentem Tiniciensem cum mansionariis habita et obtenta speciali licencia et commissione domini episcopi Cracoviensis pro tempore existentis sicut superintendentis ad hoc, videlicet ad prepositum et mansionarios, et facta sufficienti inquisitione de eodem preposito et recepto testimonio sufficienti per iuramentum corporale a tribus sacerdotibus ecclesie aut ab aliis personis secularibus fidedignis et secundum demerita eiusdem prepositi deponatur de prepositura et alius per mansionarios [k. 56v] ex eisdem mansionariis eligatur et nobis cum conventu nostro monasterii nostri Thiniciensis representetur et nos eundem electum in prepositum per eosdem mansionarios per literas nostras patentes domino episcopo Cracouiensi pro tempore existenti presentabimus pro institucione ad eandem preposituram. Et ille destitutus prepositus revertatur seu restituatur in locum sue mansionarie et vivat cum fratribus in timore Dei et charitate. Si tamen ille depositus prepositus noluerit dimittere preposituram aut locum, aut eciam esset discors inter fratres, excludatur et de mansionaria, et privetur ea per dominum abbatem pro tempore existentem et mansionarios, auctoritate domini episcopi Cracouiensis sicut superintendentis super predictum prepositum et mansionarios. Ipsi itaque predicti prepositus et mansionarii in communi fraterne vivant et charitate in spiritu Dei commaneant, anteponentes prefferentesque in cordibus suis vite sue caduce unanimitatem spiritus et zelum sanctum, modestiam, virtutem et honestatem religioseque vite famam, qua virtute nihil prestancius. Officia insuper diurna pariter et nocturna cum devocione et diligencia timoreque Dei solicite non festinando neque balbuciendo sed concine et tractim canendo in Dei nomine perfficiant Deo summo in honorem, hominibus vero in exemplarem vitam, ut ipso rectore et duce per hec sancte pietatis opera dum pro caducis eterna recipiemus, mereamur in celis condignis meritis repremiari. Rogamus itaque atque humiliter supplicamus, reverendissime in Christo pater et domine domine Joannes Dei gratia episcope Cracouiensis, ut vestra reverendissima paternitas ad ipsius ecclesie Benedicte [k. 57r] Trinitatis Virginisque Marie Assumpcionis ac beati Sthephani regis Vngarie necnon omnium sanctorum patronorum eiusdem ecclesie exaltacionem et gloriam celsiorem cultusque sacri augmentum vota et ordinaciones has nostras in omnibus et singulis clausulis et punctis hic descriptis benigne ac dignanter suscipiat, admittat et confirmet defectusque supleat prout ad 
vestre reverendissime paternitatis officium pastorale pertinere dinoscitur, premium ab immortali Deo copiossissimum perceptura nosque in devotissimis precibus atque obsequiis assiduis et constantissimos erga paternitatem vestram reverendissimam efficiendo. Ut autem nostra presens deliberacio et ordinacio sorciatur effectum suum, prefatum dominum Nicolaum de Koprzywnycza modernum rectorem dicte ecclesie in Maiori Xyansznycze in prepositum novum eiusdem ecclesie in Xyasznycze instituendum eundem vestre reverendissime paternitati presentamus per presentes. In cuius rei testimonium sigilla nostra presentibus sunt appensa. Datum in monasterio nostro Thiniciensi die Martis XVI mensis May anno salutis nostre millesimo quingentesimo octavo.

Nos itaque Ioannes Dei gratia episcopus Cracouiensis memoratus, sollicita nostri pectoris meditacione piisque permoti studiis cupientes, ut ubique in nostra dyocesi Cracouiensi cultus divinus reffloreat, in premissisque mature et digeste procedere volentes, visis et recensitis litteris preinsertis ecclesie in Maiori Xyasznycze predicte patronorum nostras cride sive citacionis litteras iuxta patrie morem contra omnes sua interesse putantes et quos presens dinoscitur tangere negocium premisimus exequendum. In quarum termino nullo penitus repungnante [k. 57v] seu contradicente spontanea insuper voluntate et libero consensu honorabilis Nicolai de Koprzywnicza ecclesie prefate rectoris et plebani prefati ad id accedendi titulum plebanatus penitus et omnimodo extingwendo ipsam ecclesiam in Maiori Xyansznicze antea parochialem nunccupatam titulo et vocabulo ac dignitate prepositure insinguivimus, extulimus et intitulavimus, ac de ipsa ecclesia parrochiali preposituram erigimus, creamus, insiguimus, extollimus et intitulamus deinceps per presentes, ac ipsum dominum Nicolaum rectorem modernum suosque successores pro tempore existentes prepositos vocari, titulari et appelari ac scribi volentes, et statuentes temporibus perpetuis et eviternis literasque preinsertas et omnia in eis contenta in omnibus clausulis et punctis admittimus, approbamus et confirmamus in Dei nomine per presentes, et ut maior decus laudis divine magis in ipsa ecclesia de cetero altissimo Deo et sue Genitrici persolvende et impendende per ministros seu per mansionarios infrascriptos illic instituendos et locandos augeatur et accrescat in ipsa ecclesia, quatuor mansionarios actu presbiteros seculares perpetuos, quintum magistrum schole manualem et amovibilem per ipsum prepositum pro tempore existentem instituimus, creavimus et locavimus, prout instituimus, creamus et locamus per presentes pro horis sive cursu de Domina in ipsa ecclesia a modo decantandis et quottidie explendis. Qui quidem mansionarii perpetui numero quatuor debebunt singulis diebus cursum et horas huiusmodi ex integro horis competentibus, videlicet matutinum, trium lectionum, primam, terciam, sextam, nonam, vesperas, completorium et missam de Domina nostra in cantu et voce alta in eadem ecclesia complere et cantare. Quos [k. 58r] mansionarios predictos prepositus una cum abbate prefati aut, ubi ipsi essent negligentes, extunc nos seu successores nostri episcopi Cracouienses pro tempore existen- 
tes, pro excessibus eorum corrigent et deponent ex legittimis tamen causis, utpote rebellionis, inobedientie, incontinentie, ebrietatis et similibus, ad quod consciencias ipsorum oneramus. Volumus eciam et statuimus ut predicti mansionarii nichil diminuant neque obmittant in divinis officiis, sed prout solitum et consvetum erat ab antiquo, volumus eos tenere et cantare in eadem ecclesia, utpote diebus dominicis et festivis, eciam et ferialibus, ad quod sint obligati, summa missa vero de die correspondens officio diei, missa vero de Domina nostra pro maneria cantabitur. Volumus eciam ut predicti prepositus et mansionarii statuta per eos condita teneant, secundum que vivere et regere se debebunt, tam in ecclesia quam in domo, secundum ordinacionem privilegii domini abbatis et conventus Tiniciensis monasterii, prout supra tactum est, que nos presentibus gratifficamus et confirmamus cum effectu. Et illa statuta, que in posterum edita erunt pro utilitate ecclesie et domus ac predictorum prepositi et mansionariorum licita, rata eciam et grata ratificamus et confirmamus per nos et successores nostros episcopos. Verum ut is, qui fert onus, ferat et commodum, et qui altari servit, de altari et vivat, primo predicti mansionarii habebunt decimas in villis, videlicet Modrzani, Dzczyszlawycze, Jankowycze, Barczkow, Maczyczyna et decimam post tabernam in Maiori Xyasznycze. Item columbacionem totam peccunialem post totam parochiam cum denario sancti Petri, de qua columbacione solvent mansionarii petronales quatuor decim scotos cum uno grosso, quittancie habebunt qui divident inter se equaliter sine iniuria uniuscuiusque. Item columbacio quem datur [k. 58v] in provisionibus post villas, tota cedat pro mansionariis in comune pro eorum domo seu coquina. Harum provisionum magister schole habeat quartam partem. Item habeant predicti mansionarii duas piscinulas que iacent post horreum plebani seu prepositi pro eorum mensa. Item missas votivas tricesimas lectas vicarii seu mansionarii habebunt pro se, dividendo inter se equaliter sine iniuria uniuscuiuscumque. Item adhuc vigilias, votivas missas, tricesimas cantatas magister schole, qui cum eisdem mansionariis cantabit, cum eisdem mansionariis participabit quartam partem, prout fuit ex antiqua consvetudine. Spolium, sicut equi, boves vel aliqua alia sicut peccora, pecudes vel eciam fruges aut pannus, horum omnium prepositus primam partem percipiat, duas mansionarii et quarta pars cedat pro fabrica ecclesie. Item offertorii duas partes mansionarii habeant, prepositus terciam et magister schole quartam. Quos proventus cum oblacionibus et questibus ex antiquo pertinentibus ipsis preposito et mansionariis seu vicariis tenore presencium perpetuo ascribimus et invisceramus integre. Et si quid im posterum eisdem fuerit assignatum vel donatum tam in neccuniis quam censibus ant agris seu domibus, eciam presentibus ratificamus approbamusque et confirmamus per nos et successores nostros ratum et gratum habebimus et ne im posterum vertatur in dubium, de proventibus ad prepositum pertinentibus duximus declarandum. Ex deinceps prepositus pro dote prepositure sue predicte habere debet, primo predium ex antiquo plebanale cum agris et pratis omnibus ad ipsum predium pertinentibus ac partem gay emensurati ex antiquo de rubetis 
cum lacu sub villa Maczyczyna, prout antecessores sui cum decimis et cultura sua hactenus recipiebant [k. 59r] et habebant. Item decimas in villis monasterii Thiniciensis in Minori Xyasznycze et in villa militari nobilis domini Przeczyeszky in Moykovycze, duas ortulanias in Maiori Xyasznicze cum decimis post eosdem ortulanos. ${ }^{a}$ Item offertorii de ecclesia unam partem, duas vicarii seu mansionarii et quartam magister schole. Prepositus habeat eciam tabernam in Maiori Xyasznycze cum piscina. Que piscina iacet penes eandem tabernam in Maiori Xyasznicze, que piscina data est per abbatem et conventum monasterii Thiniciensis preposito, de qua taberna plebani hereditaria solvuntur ab antiquo et secundum privilegium eiusdem thabernatoris quatuor marce peccuniarum pro festo Nativitatis sancte Marie. De quibus quatuor marcis provenientibus ex eadem tribus solvet prepositus rectori seu magistro schole predicto tres marcas racione laborum suorum. Residuum tollet prepositus, videlicet quartam marcam pro $\mathrm{se}^{\mathrm{a}}$. Item aduc prepositus habeat aliam piscinam, que iacet penes agrum plebani alias Oszthrow post tabernam plebani, que nunc est deserta, et que ex antiquo est plebani. Item predictus dominus Nicolaus de Koprzywnycza, constructor eiusdem ecclesie et cooperator harum mansionariarum multorumque ornamentorum ac aliarum rerum multarum donator, post cessum vel decessum ipsius eodem ecclesie in dicta Maiori Xyasznycze dat et legat omnia bona sua per eum acquisita gravissimis laboribus et sudoribus et ex serviciis suis. Illa bona, videlicet, que sunt in predicta ecclesia per eum comparata, sicut calices, cruces, casulas, libros et alia multa ornamenta in eadem ecclesia et in dote plebanali seu prepositura, tam mobilia quam immobilia sicut omnia peccora, pecudes, equos, boves, fruges tam in horreo quam in campis seminata, eciam in decimis, currus omnes sufferratos [k.59v] et non sufferratos, eciam et tectum currum panno omnesque res seu instrumenta ad colendum agros et eciam omnia suppellectilia et utensilia tocius domus, que eciam pertinent ad coquinam et ad mensam, eciam scutellas staneas et coclearia argentea, que erunt ibi in Xyasznycze, nichil excipiendo, solum ut solvatur salarium familie domus ex hiis bonis et debita probabilia, si que erunt; tali tamen condicione, ut predictus successor prepositus et quilibet eorum in perpetuum electus per mansionarios et confirmatus per episcopum utatur hiis bonis solum ad vitam existens in humanis, post vitam vero suam omnia cedant pro successore, ita quod nichil alienare prepositus poterit neque potest neque eciam testamentum de eisdem rebus et bonis alicui extraneo facere neque dare eciam et consanguineis, preter vestes

a-a Na marginesie inną ręką zamiast przekreślonego następującego tekstu:

Eiusdem tabernatoris quatuor marcas peccuniarum pro festo Nativitatis Sancte Marie, de quibus quatuor marcis provenientibus ex eadem taberna solvet prepositus rectori seu magistro schole predicto tres marcas racione laborum suorum. Residuum tollet prepositus, videlicet quartam marcam pro se. Item offertorii de ecclesia unam partem, duas vicarii seu mansionarii et quartam magister schole. Prepositus habeat eciam tabernam in Maiori Xyasznycze cum piscina. Que piscina iacet penes eandem tabernam in Maiori Xyasznycze, que piscina data est per abbatem et conventum monasterii Thiniciensis preposito, de qua taberna plebani hereditaria solvuntur ab antiquo et secundum privilegium. 
suas in quibus incedebat seu ea deferebat. Poterit tamen sibi eligere executores, non tamen alios nisi confratres suos mansionarios, qui erunt omnium derelictorum patroni et provisores post mortem prepositi predicti. Qui quidem mansionarii habebunt curam et diligenciam de omnibus rebus tam spiritualibus quam temporalibus eiusdem prepositure usque ad institucionem novi prepositi. Cui preposito novo predicti mansionarii tenebuntur facere racionem de omnibus rebus perceptis et expositis per eosdem mansionarios. Et idem novus prepositus presentabit et dabit alium mansionarium, quartum in locum suum, videlicet rectorem seu magistrum schole, si erit ad hoc abilis et idoneus et ut promoveatur infra unum annum in presbiterum. Et quia beneficium datur propter officium, equum et iustum censemus volumusque, ut pro tali predicto domino Nicolao de Koprzywnycza moderno preposito et constructore eiusdem ecclesie in Xyasznycze, altariste ecclesie [k. 60r] nostre cathedralis Cracouiensis, peregrini Jerosolimitani, benefactore cooperatoreque horum mansionariorum multorumque ornamentorum ac aliarum rerum multarum donatore eidem ecclesie in Maiori Xyasznycze, memoria habeatur per eosdem prepositum et mansionarios eviterne et in perpetuum, primo ut in qualibet missa, que cantabitur per predictos mansionarios Salve Sancta Parens, imponatur collecta pro anima eiusdem domini Nicolai seu pro sacerdote. Item missam unam semel in septimana legant predicti mansionarii secundum ordinem vigiliasque novem leccionum semel eciam in anno in die deposicionis sue et in crastino missam decantabunt. Idem eciam prepositus cum mansionariis facient commemoracionem ad populum in quolibet eorum sermone pro anima eiusdem domini Nicolai sub pena excommunicacionis et eterne dampnacionis. Volumus eciam ut quilibet prepositus existens in humanis pro antecessore suo seu antecessoribus suis legat unam missam semcl in septimana per se vel per alium racione laborum et bonorum eorundem antecessorum suorum per eos derelictorum sub pena excommunicacionis. Item statuimus et ordinamus, quod predictus prepositus una cum mansionariis sint monoculi, ita quod nullum beneficium aliud [dod.: curatum] audeat quis habere seu tenere cum prepositura eadem aut mansionaria preter modernum dominum Nicolaum rectorem et specialem benefactorem eiusdem ecclesie in Maiori Xyasznycze cooperatoremque horum mansionariorum, qui poterit plura beneficia habere et tenere in vita sua cum eadem prepositura. Cui admittimus et cum eodem domino Nicolao rectore seu preposito dispensamus. Post decessum vero suum aut eciam cessum nullus successor suus audere habere seu tenere aliud beneficium [dopis.: curatum] nisi eandem preposituram aut mansionariam. Si guis ausu temerario hoc fecerit, ipso facto volumus eandem preposituram seu mansionariam vacare. Quorum [k. 60v] consciencias obligamus sub pena excommunicacionis similiterque cum predicto domino Nicolao de Koprzywnycza preposito iam moderno de et super residencia continua circa dictam ecclesiam seu preposituram in Xyasznycze in Dei nomine dispensamus per presentes. Quam dispensacionem ad successores dicti domini Nicolai nolumus extendi. Item volumus et statuimus, quod 
si aliquis ex mansionariis vellet resignare suam mansionariam, quod dictam resignacionem non poterit facere in favorem alicuius certe persone, sed simpliciter eandem faciat in manibus dicti prepositi et prepositus procedet ad electionem seu vocacionem alterius mansionarii acsi per mortem vacaret. Idem eciam volumus intelligi et de preposito. Item volumus eciam, quod si et in quantum fuerit predictus prepositus negligens circa ecclesiam in officio divino aut eciam in dote prepositure sue circa labores domesticos aut prodigus aut scandalosus esset, ita quod bona ecclesie et in dote sue prepositure per suam inadvertenciam aut incurabilitatem anichilaret, dilapidaret vel diminueret non augmentando, sed ea bona diminuendo, ille prepositus per dominum abbatem Thiniciensem pro tempore existentem cum mansionariis, habita et obtenta speciali licencia et commisione nostra et successorum nostrorum episcoporum ecclesie Cracouiensiis pro tempore existencium sicut superintendencium ad predictos prepositum et mansionarios, facta prius sufficienti inquisicione de eodem preposito et recepto testimonio sufficienti per iuramentum a tribus sacerdotibus ecclesie aut eciam ab aliis personis secularibus fidedignis, et secundum demerita eiusdem prepositi, deponatur de prepositura et alius ex mansionariis eligatur per eosdem mansionarios et domino abbati et suo conventu Thiniciensi reputetur. Et dominus abbas cum conventu suo per litteras suas patentes remittat ad nos et ad successores [k. 61r] nostros pro institucione et confirmacione. Et ille destitutus prepositus revertatur seu restituatur in locum sue mansionarie et vivat cum fratribus in timore Dei et in charitate Cristi pacifice et humiliter. Si tamen ille depositus prepositus noluerit dimittere preposituram aut locum, aut eciam esset discors inter fratres vel rebellis aut inobediens in mansionaria inter fratres, excludatur et de mansionaria et privetur ea per dominum abbatem Thiniciensem pro tempore existentem et mansionarios auctoritate nostra et successorum nostrorum episcoporum ecclesie Cracoviensis sicut superintendencium supradictum prepositum et mansionarios, decernentes omnia premissa per nos sic ordinata et salubriter facta habere robur perpetue firmitatis in omnibus clausulis et punctis superius notatis et scriptis. Quibus omnibus premissis ac statutis edendis auctoritatem nostram presentibus alios quosvis defectus supplentes interponimus pariter et decretum.

In quorum omnium et singulorum fidem et testimonium premissorum presentes nostras erectionis, fundacionis et confirmacionis literas scribi mandavimus nostrique sigilli appensione iussimus et fecimus communiri. Actum et datum Cracouie anno Domini millesimo quingentesimo octavo indiccione vndecima die vero Mercurii decima septima mensis May pontificatus sanctissimi in Christo patris et domini nostri domini Julii divina providencia pape secundi anno ipsius tercio in capitulo generali pro festo sancti Stanislai in mense Maii celebrato. Presentibus ibidem venerabilibus dominis Iohanne Lathalszky preposito, Nicolao Bedlennszky scolastico, Petro Wapowszky de Radochowycze[!] cantore, Andrea Rapsztynszky, Johanne Podlodowszky, Iohanne Botorzynszky, Sigismundo Thargowyczszky, Nicolao 
[Czepiel], Iohanne Rosztowszky, Mathia de Schydlow, Iohanne [k. 61v] Szalomon, Iohanne de Oszwyaczym, Johanne Karnkowszky, Mathia Grodzyczszky, Thoma Rosznowszky, Jacobo Szthaskowszky, Iohanne Jakwbowszky, Mathia Raczyasz, Jacobo de Erczyeszow prelatis et canonicis ecclesie nostre cathedralis Cracouiensis, Iohanne Szyrthowszky, Martino de Szbyky, Augustino de Barwthow, Iohanne Yaszthrzambszky notariis curie nostre episcopalis publicis et aliis quam pluribus testibus fidedignis ad premissa vocatis. [Znak notarialny Stanisława ze Sandomierza]. Et ego Stanislaus Baltasaris de Szadomyrya clericus Cracouiensis diocesis publicus apostolica auctoritate notarius et coram memorato reverendissimo in Cristo patre et domino domino Ioanne Dei gratia episcopo Cracouiensi facti presentis scriba quia predictis literarum preinsertarum exhibicioni, erectioni, fundacioni, confirmacioni et earundem decreto aliisque omnibus et singulis premissis dum sic eo modo, ut premittitur fierent et agerentur una cum prenominatis testibus presens interfui eaque omnia et singula premissa sic fieri vidi et audivi, ideo has presentes erectionis literas manu alterius fidelis et legalis notarii, me protunc aliis arduis occupato negociis scriptas exinde confeci, subscripsi et publicavi et in hanc publicam formam redegi signoque et nomine meis solitis et consvetis una cum appensione sigilli memorati reverendissimi in Christo patris domini Iohannis episcopi Cracouiensis communivi et consignavi in fidem, robur et testimonium omnium et singulorum premissorum, rogatus et requisitus. 